\title{
CARMEN KORDICK. THE SAINTS OF PROGRESS. A HISTORY OF COFFEE, MIGRATION, AND COSTA RICAN NATIONAL IDENTITY. TUSCALOOSA: UNIVERSITY ALABAMA PRESS, 2019
}

Carmen Caamaño Morúa

Recibido: 10/09/2019 - Aceptado: 19/09/2019

El libro The Saints of Progress. A History of Coffee, Migration, and Costa Rican National Identity fue publicado en el año 2019 por la University of Alabama Press, y corresponde a los resultados de la investigación que Carmen Kordick realizó como proyecto de graduación doctoral en Yale University (Kordick).

Se trata de un trabajo con perspectiva histórica enfocado en un periodo muy amplio que va de 1820 a los años 2000. La investigación se alimenta del estudio de archivos, así como de métodos etnográficos (observación participante, cuestionarios anónimos, historias de vida), y fue desarrollado en Tarrazú, en la zona de Los Santos en San José, Costa Rica, y en el norte de New Jersey, en Estados Unidos.

Estadounidense, de madre costarricense, Carmen Kordick busca desentrañar los misterios que para ella conlleva una narrativa idealizada de Costa Rica como país de paz e igualdad en contradicción con experiencias de conflictos políticos, de clase, etnia, género y generación en el contexto de la inserción capitalista en esta zona fundamentalmente rural de la provincia de San José. Es esta búsqueda de contradicciones la que hila los siete capítulos sobre la historia de San Marcos de Tarrazú y sus pobladores, desde su fundación a finales del siglo XIX hasta el siglo $\mathrm{XX}$.

Si bien la autora no lo establece así, en la práctica este libro se divide en tres apartados: de la Introducción al Capítulo 5, indaga en los orígenes de Tarrazú y los conflictos de clase, construcciones de género y narrativas políticas de sus habitantes. Los Capítulos 6 y 7 se refieren a la emigración de los habitantes de Tarrazú y otras zonas de Costa Rica y la forma en que reconstruyen las nociones de clase, género y nación desde el exterior. La tercera parte está conformada por las conclusiones, en donde Kordick brinda una explicación alternativa sobre las características de lo que se ha considerado la excepcionalidad de la nación costarricense.

La primera parte, contempla a su vez dos grandes temas diferenciados. El primero trata de los procesos de incorporación capitalista y modernización en esa zona 
rural, el segundo incorpora un análisis de algunos aspectos de la sociedad patriarcal que se gestionó.

Así, el texto inicia con la llegada de los primeros colonos a la zona de Tarrazú en el año 1824, procedentes de Desamparados y la posterior incorporación del cultivo del café durante la última década del siglo XIX como actividad productiva alrededor de la cual se organizó la economía local, vinculando a la zona de Los Santos con el sistema capitalista mundial. Es una trayectoria histórica en donde Kordick hace retratos de la vida de las personas en diferentes momentos culminantes, pasando por la Gran Depresión de 1929 y la Guerra Civil del 48.

En el texto, podemos identificar la forma en que capitalismo, modernidad y progreso se entrelazan estableciendo formas particulares de explotación de la fuerza de trabajo agrícola, en donde, a diferencia de lo planteado en la construcción de Costa Rica como una sociedad rural igualitaria en sus orígenes, Kordick descubre las desigualdades. Para ello, se centra en figuras como Tobías Umaña Jiménez, quién acumuló tierras a costa de la desgracia de productores campesinos a los cuales prestó dinero y despojó cuando no pudieron pagarle, especialmente durante la crisis de 1929 a 1931. En algunos casos, Umaña llegaba a convertirles en peones a su servicio por el pago de las deudas. Durante la primera mitad del siglo XX, Tobías Umaña llegó a ser dueño de muchas hectáreas de tierra, por muchos años fue el más grande productor de café y obligaba a sus peones a comprar en el comisariato de su propiedad al pagar salarios en pagarés que solamente allí tenían valor.

Por su parte, los pequeños productores y campesinos de subsistencia que tenían tierra y producían café, solamente contaban con el beneficio de Umaña, por mucho tiempo el único existente en la zona, para procesar su café, por el cual recibían pagos injustos y tardíos.

Umaña fue también funcionario en el telégrafo y perito, al cual le pagaban sus labores con terrenos que luego vendía. Si bien en 1943 se aprobó el Código de Trabajo, Umaña rotaba a sus trabajadores, despidiéndolos y volviéndolos a contratar, de manera que no fueran considerados sus derechos. Además, cuando se estableció la Fábrica Nacional de Licores, Umaña era el mayor expendedor de alcohol para el consumo local, colocándose del lado de la autoridad, el Resguardo Fiscal, que perseguía el licor de contrabando, producido de manera artesanal entre pobladores de la zona y que no pagaba impuestos. Con ejemplos extraídos de la revisión de archivos e historia oral, la autora logra retratar a Tarrazú como una sociedad profundamente desigual e injusta.

Por otro lado, la condición de despojo en que se encontraban muchos hombres frente a la pérdida de tierras, pobreza, condición de peonaje y persecución del resguardo por la producción de guarapo y chicha, es leída por Kordick como un proceso de pérdida de masculinidad.

Así, desde una perspectiva de género, Carmen Kordick revela a Tarrazú como una sociedad patriarcal, en donde la construcción de masculinidades está vinculada 
con el consumo de alcohol, las peleas callejeras, la violencia hacia mujeres, niños y niñas, e incluso, la participación política, como es el caso del apoyo a Figueres en la Guerra Civil de 1948. Coincide así con hallazgos de Manuel Solís sobre la violencia de este periodo en el país (Solís Avendaño).

Mientras tanto, las mujeres, que no controlaban sus cuerpos, no salían de sus casas, ni tenían acceso a espacios sociales diferentes a la iglesia o los festejos populares. Ellas estaban sometidas a sus maridos, padres, hermanos o hijos y solamente tenían acceso a trabajar escogiendo café cosechado o como trabajadoras domésticas. En este último caso, quedaban expuestas a maltrato y abuso de los patrones y sus hijos. Esto hacía que las mujeres de bajos recursos económicos sufrieran más agresión. Además, en su propio hogar sufrían infidelidades y violencia por parte de esposos y/o familiares alcoholizados que, aun así, estaban a cargo de guardar su honor, dependiendo de ellos su identidad y los recursos para la supervivencia de ellas y sus hijos e hijas.

En este contexto, Kordick encuentra evidencias de femicidios que quedaron impunes con la complicidad de autoridades políticas y religiosas, pues la violencia doméstica estaba naturalizada.

También, Kordick plantea que existían muchos resentimientos en contra de la autoridad, y agradecimiento hacia el presidente Cortés por el Decreto de 1937 que creó un servicio público de crédito agrícola, con el cual quitaban a Umaña el monopolio de los préstamos. Esto explica, según la autora, que los hombres se levantaran en armas junto a José Figueres en la guerra del 48 para hacer valer su voto. Esto último fue determinante porque la posibilidad de votar era un componente más de la hombría, la cual se veía amenazada ya que, desde las elecciones de 1944, se hablaba de fraude electoral.

La participación en la guerra del 48 generó una demanda de reconocimiento y mejoras en Tarrazú pero, aunque se aprobó una ley de cooperativas que mejoraron las condiciones de los productores y facilitaron la provisión de electricidad en la zona, existe una narrativa de que los tarrazuceños fueron olvidados.

Sin duda, cuando se visita la zona de Los Santos, Tarrazú incluido, la experiencia resulta sumamente contradictoria. El verde paisaje y la amabilidad de la población contrastan con el sufrimiento que se percibe en la zona y Carmen Kordick nos presenta con importantes elementos históricos que podrían explicar su origen.

En mis propias investigaciones realizadas ya hace años (Caamaño Morúa), pude constatar situaciones de pobreza, abandono y violencia patriarcal que persisten hasta nuestros días. Diferentes mujeres entrevistadas me hablaron de vivencias de incesto, depresión, alcoholismo, suicidio y enfermedad mental entre familiares y vecinos. Sin embargo, también plantearon formas de resistencia frente a la violencia (Caamaño Morúa, Las "mujeres solas"), un aspecto que no aparece en el texto de Kordick pero que debió haber estado allí desde el principio.

En la segunda parte del libro, es decir, los capítulos 6 y 7, la autora analiza la migración desde y hacia la zona como un fenómeno que transforma las relaciones de 
clase y raza, así como las identidades nacionales. De esta manera documenta que, desde los años de 1960 y 1970 iniciaron las migraciones desde Tarrazú hacia New Jersey, Estados Unidos, siendo la familia Cárdenas la pionera.

Mediante trabajo de campo en Paterson, New Jersey, sitio en donde está la más alta concentración de tarrazuceños, y otras localidades cercanas, Kordick examina la forma en que estos inmigrantes construyen la mirada sobre Costa Rica a partir de la idea del excepcionalismo político, la visión ecoturística externa del país, el consumo de productos nacionales, la recreación de espacios sociales y de celebración patria con connacionales. Sin embargo, establece que las personas también entran en contradicción al tener diferentes experiencias referidas a desigualdades de clase y etnia, tanto en New Jersey como en Tarrazú, y al tener poca atención por parte del gobierno de Costa Rica a través del consulado que les corresponde. Estas experiencias, en algunos casos, hacen aparecer a Costa Rica como similar a otros países de Centroamérica, lo que cuestiona el excepcionalismo costarricense.

Ambas partes del texto son de naturaleza diferente, tanto por la metodología empleada como el periodo al que se refieren y la narrativa que las sostiene, presentando discontinuidades con respecto a las categorías de análisis utilizadas. A mi parecer, en la segunda parte, el contexto social y político que da lugar a las migraciones no se analiza de manera suficiente y quedan perdidas en el camino las desigualdades de clase y género que impulsaron a las personas de la zona de Los Santos a emigrar.

Podríamos decir que la autora nos presenta con diversas fotografías a las personas de Tarrazú en diferentes épocas y espacios con la idea de deconstruir el mito nacional sobre el país igualitario, blanco y pacífico. Encuentra, efectivamente, un espacio rural en donde existen desigualdades de clase desde el inicio, las cuales se sostienen a través de los años a pesar de la modernización que trajo la producción del café. También descubre un mundo patriarcal en el que las mujeres tienen muy poco control sobre sus cuerpos y sus vidas y los hombres aparecen como gestores de violencia debido a procesos de despojo económico, social y político. Sin embargo, no queda tan claro de qué manera estas condiciones están presentes en la comunidad transnacional de Tarrazú. Es decir, la fotografía que realiza la autora sobre las migraciones no logra profundizar en los procesos de construcción de clase y género en relación con la primera parte del texto. En esta segunda parte aparece, por otro lado, la categoría de raza como un elemento a considerar en la distancia de la población emigrante frente a las construcciones de las personas costarricenses como blancas y que no ha sido trabajada a fondo en la primera parte.

Mientras tanto, las conclusiones conforman una tercera parte, pues se refieren a aspectos que no se habían tratado en el resto del texto, brindando elementos nuevos de interpretación al considerar la relación entre Estados Unidos y Costa Rica durante 
la Guerra Fría como un asunto fundamental del desarrollo costarricense. Aquí concluye la autora que la producción de café no fue un igualador socioeconómico y que este papel lo asumieron las instituciones que se crearon en los años cuarenta, las cuales aminoraron las tensiones de clase, al mismo tiempo que se proscribía el Partido Comunista y muchos de sus miembros salían al exilio, lo que favoreció las relaciones con Estados Unidos. Pero esta interpretación más general para el país no se contrasta con la experiencia específica de Tarrazú que venía siendo la tónica en la primera parte, ni con la experiencia de las personas que emigraron que se explora en la segunda parte.

A pesar de estas discontinuidades en la narrativa de la historia de Tarrazú y de sus habitantes, Carmen Kordick nos presenta un material sumamente valioso para comprender, desde diversas perspectivas, aspectos que usualmente son rechazados en nuestro imaginario social de Estado Nación costarricense y que nos asemejan al resto de naciones latinoamericanas en donde colonialismo, patriarcado y capitalismo (Segato) conformaron la estructura sobre la cual múltiples desigualdades e injusticias se han asentado.

Esperamos que pronto podamos contar con este texto en español para su mayor difusión.

\section{Bibliografía}

Caamaño Morúa, Carmen. Entre "Arriba" y "Abajo": La experiencia transnacional de la migración de costarricenses hacia Estados Unidos. San José: Editorial de la Universidad de Costa Rica, 2010.

Caamaño Morúa, Carmen. «Las "mujeres solas" de Los Santos: Discursos de control y estrategias de resistencia.» Cárdenas, Eliana y Ligia Sierra. Encuentros y Divergencias, Dinámicas migratorias desde la Frontera sur. Quintana Roo: Universidad de Quintana Roo, 2013. 243-270.

Kordick, Carmen. The Saints of Progress. A History of Coffee, Migration, and Costa Rican National Identity. Tuscaloosa: The University of Alabama Press, 2019.

Segato, Rita. La guerra contra las mujeres. Madrid: Traficante de Sueños., 2016.

Solís Avendaño, Manuel A. Memoria descartada y sufrimiento invisibilizado. La violencia política de losaños 40 vista desde el Hospital Psiquiátrico. San José: Editorial de la Universidad de Costa Rica, 2013.

Carmen Caamaño Morúa. Costarricense. Psicóloga. Docente en la Escuela de Psicología e investigadora en el Instituto de Investigaciones Sociales de la Universidad de Costa Rica. Entre sus artículos más recientes se encuentra "Sensibilización sobre la equidad de género, conflicto y políticas de equidad e inclusión en la Universidad-Empresa: El caso de la Universidad de Costa Rica". Igualdad sustantiva en las 
instituciones de educación superior. Editado por María José García Oramas. Universidad Veracruzana, 2018, pp. 49-81; y Desarrollo, migración, y las mujeres como espacio social de disputa. Miradas sentidas y situadas. Experiencias con grupos y comunidades. Ignacio Dobles, Adriana Maroto, María José Masís, Adriana Rodríguez, (Eds.). San José: Editorial de la Universidad de Costa Rica, 2017, pp. 79-98.

Contacto: carmen.caamano@ucr.ac.cr

ORCID: 0000-0001-7038-8301 